
\title{
TRABALHO A PARTIR DA PRIMEIRA INSERÇÃO: O CASO DE SÍSIFO EM MARACANAÚ - CEARÁ, BRASIL
}

\author{
TRAJECTORIES OF YOUNG PEOPLE IN THE \\ WORLD OF WORK FROM THE FIRST INSERTION: \\ THE CASE OF SISYPHUS MARACANAÚ - IN CEARÁ, BRAZIL
}

Nara Maria Forte Diogo Rocha

Universidade Federal do Ceará, Sobral, Brasil

Cezar Wagner de Lima Góis

Universidade Federal do Ceará, Fortaleza, Brasil

\begin{abstract}
RESUMO
Essa investigação diz respeito à vida de um jovem, chamado de Sísifo, que conseguiu seu primeiro emprego através de uma política pública do município de Maracanaú. Objetiva-se estudar o movimento da identidade pessoal de jovens na situação de primeira inserção, fundamentando-se na Psicologia Histórico-Cultural da Mente e na Psicologia Social Crítica. Discute-se, ainda, juventude e o processo de exclusão social. Foi utilizada metodologia qualitativa, mediante entrevistas orientadas em três momentos distintos, com intervalo de dois meses e posterior realização de análise temática. A partir de seus relatos, é possível compreender que o trabalho facilita o movimento da identidade na direção do Valor Pessoal e Poder Pessoal, de modo complexo e não-linear, alimentado pelas contradições da realidade em que vive.
\end{abstract}

Palavras-chave: identidade; inserção profissional; juventude.

\begin{abstract}
This research concerns the life of a young man named Sisyphus, who got his first job through a public policy of the municipality of Maracanaú, state of Ceará. This study focuses on the movement of Personal Identity in the situation of young first-insertion, basing on the Historical-Cultural Psychology of Mind and Social Psychology Review. It was also discussed youth and social exclusion process. It was defined a qualitative methodology with analysis of content. Qualitative methodology was used by targeted interviews in three separate stages with an interval of two months and subsequent thematic analysis. From his reports, it is possible to understand that Working facilitates the Identity movement in the direction of the Personal Value and Personal Power, in a complex and nonlinear way, nourished by the contradictions of the reality in which he lives.
\end{abstract}

Keywords: youth; professional insertion; identity.

\section{Introdução}

Zeus ordenou a Sísifo a condenação de rolar enorme pedra ao cume de uma alta montanha. Sempre que Sísifo divisava o topo, a pedra despencava do rochedo, obrigando o personagem a retomar o exaustivo trabalho. O codinome Sísifo foi escolhido para o jovem participante deste estudo pelos vestígios do mito grego que aparecem em sua fala. A inserção dos jovens no mercado de trabalho atualmente ganha ares de jornada mítica, cuja tarefa consiste em conseguir a primeira oportunidade.

A vida de dez jovens foi acompanhada durante o ano de 2004, quando conseguiram sua primeira colocação profissional através de uma política pública de geração de emprego e renda para jovens. Objetivou-se investigar o movimento da Identidade Pessoal de jovens que estivessem em fase de inserção no mercado de trabalho por intermédio do projeto Emprego Jovem da Prefeitura Municipal de Maracanaú, compreendendo papéis e persona- 
gens vivenciados e abandonados pelos jovens por ocasião da inserção profissional à luz das categorias Identidade Pessoal e Trabalho. Investigou-se, ainda, a relação entre inserção profissional e projeto de vida dos jovens.

Sísifo ingressa no trabalho formal por meio de uma iniciativa pioneira em termos de políticas públicas no Brasil na ocasião: o projeto Emprego Jovem, implementado em Maracanaú - região metropolitana de Fortaleza, Ceará. Lançado em abril de 2003 pela Lei Municipal $\mathrm{n}^{\circ}$ 895, antes mesmo do Programa Nacional Primeiro Emprego, o Projeto Emprego Jovem visava a facilitar a inserção profissional de jovens de Maracanaú, entre 18 e 24 anos, sem experiência formal no mercado de trabalho, mediante subsídio municipal (meio salário mínimo para cada jovem admitido) às empresas que aderissem ao projeto. A cidade faz parte da área metropolitana da capital e possui cerca de 200 mil habitantes, dos quais aproximadamente 25 mil têm entre 18 e 24 anos. Apresenta uma das maiores rendas per capita do estado e uma das maiores concentrações de renda $-75 \%$ da população sobrevive com menos de dois salários mínimos.

A Identidade Pessoal foi abordada a partir do conceito de Identidade Metamorfose, a identidade como processo (Ciampa, 2001), que se constrói por meio dos movimentos de manutenção e negação do vir a ser como faces da mesma moeda. É uma categoria referencial e relacional, ou seja, de acordo com Berger e Luckmann (1985), serve como localização em um mundo e é forjada a partir das relações de igualdade e diferença que o sujeito estabelece.

O processo de inserção profissional é visto como um momento que altera o modo de vida do sujeito, sua localização no mundo e sua relação com os outros. Esta pesquisa investigou de que forma esse momento se reflete na Identidade Pessoal, que até então seguia um curso de movimento.

Esse estudo está localizado dentro do referencial mais amplo da Psicologia Comunitária que envolve a Pedagogia da Libertação, a Psicologia Social Crítica, a Psicologia Histórico-Cultural e a Educação Biocêntrica, tendo sido tratadas as categorias Trabalho, Identidade Pessoal, Juventude e Exclusão Social a partir desse enfoque.

\subsection{Questões contextuais com relação à juventude e trabalho}

Ao iniciar os estudos sobre trabalho, reconhece-se uma série de questionamentos sobre sua centralidade para a sociedade atual, decorrente das rápidas transformações do mercado como ponto de pauta sempre presente nesse debate. Essas transformações implicam a necessidade constante de (re)qualificação do trabalhador e o aprimoramento de suas habilidades e competências subjetivas. As relações de trabalho se alteram e, enquanto uma grande parcela da população não consegue retor- nar à condição de empregado formal, outra boa parte não consegue ingressar nela. Na descrição dessa situação, há, muitas vezes, uma referência ao mundo do trabalho como instância de deliberação superior, uma entidade autônoma que decide quem tem ou não condições de realizar trabalho, à qual os indivíduos submetem-se em função da necessidade de sobrevivência. São comuns expressões referentes às "demandas colocadas pelo mundo do trabalho" ou à "lógica do mercado", como se a realidade social não fosse produzida, mantida e transformada por sujeitos, coletivamente.

Para além das expressões de uso cotidiano que dizem respeito a uma visão de mundo nem sempre refletida, constata-se o que Hirata (1994) aponta: a divisão do trabalho prescinde cada vez mais dos limites técnicos dos postos de trabalho, exigindo a cooperação entre empregado e empresa e o trabalho de equipe. A qualificação do empregado não é descartada, mas já não é suficiente. A descrição de tais postos ressalta, hoje, componentes "implícitos", enfatizando saberes tácitos e qualidades pessoais. Observa-se que mesmo o perfil das funções mais elementares e mais repetitivas considera fundamentais características pessoais como automotivação, capacidade de trabalhar em equipe, além da exigência das habilidades básicas, como ler, escrever e fazer contas, ou alguma capacitação técnica mais específica - as competências.

No mundo do trabalho, há um acelerado desenvolvimento tecnológico que foi acompanhado por inovações na área da organização da produção, gerando novos modelos, de acordo com Leite (1994), como as técnicas japonesas: just-in-time, Kanbam, Kaizen, organização celular, entre outras. Há um retraimento do crescimento econômico, o mercado se torna cada vez mais competitivo. Embora os processos convencionais de trabalho permaneçam em várias indústrias brasileiras, o perfil do emprego industrial se transforma, como aponta Leite (1994), com a exigência de mais qualidades comportamentais e maior escolaridade formal. $\mathrm{O}$ autor revela ainda a utilização predatória da força de trabalho, pela ausência de incentivo à educação, a baixa escolaridade dos trabalhadores e os baixos salários que provocam uma alta rotatividade no setor. A sociedade que, em um momento de crescimento econômico, se estrutura em torno do emprego e se resguarda muito pouco do desemprego, encontra-se, atualmente, como caracteriza Antunes (1995), num momento de metamorfose devido ao retraimento dessa situação e consequente redução dos postos de trabalho. Tal quadro sugere o questionamento da centralidade do trabalho para a vida humana no momento atual. Para Antunes (1995), o trabalho como "protoforma da atividade humana" pode ser o ponto de partida para uma sociedade que venha a transcendê-lo. Essas transformações refletem-se no modo como os jovens agem no mundo. Se antigamente havia uma 
preocupação com a escolha vocacional, hoje o jovem procura estruturar um projeto de vida capaz de lidar com um nível muito maior de incerteza. Como apontam Sarriera, Berlim, Verdim e Câmara (2000), em estudo sobre a identidade ocupacional de jovens de classes populares, os programas e projetos de inserção no mercado de trabalho não devem ser meramente adaptativos, e sim promover reflexão sobre as condições de vida e formas de buscarem os sonhos.

Pochmann (2002) avalia que nos anos 90 houve uma retração nos postos de trabalho ocupados por jovens. Além disso, adultos passaram a competir pelas poucas vagas existentes. Tal situação não tem precedentes. A saída adotada pelos países desenvolvidos foi ampliar o tempo de estudo. Leite (2003) afirma que a tendência dos últimos 20 anos foi tratar a questão do trabalho jovem a partir de um olhar "vitimizador" do jovem latino-americano, obrigado a trabalhar, quando o "certo" seria estudar por mais tempo. Coincidentemente, Leite (2003) localiza nos anos 90 o surgimento de uma nova tendência de análise do trabalho jovem, no sentido de reconhecer a presença dessa prática como expressão do ator social que lida com as injustiças.

A primeira inserção dos jovens no mundo do trabalho é crivada de paradoxos, como, por exemplo, o requisito de experiência anterior para quase todos os postos de trabalho. Alguns jovens, chamados pela sobrevivência a resolver esse enigma, enxergavam na "competência" uma fresta de luz atravessando as portas fechadas do mercado de trabalho, depositando suas esperanças em relação ao emprego no desenvolvimento de certas qualidades pessoais e técnicas. O que parece ser a resposta para os jovens deriva, porém, de uma ideologia neoliberal que prima pela meritocracia e pelo individualismo. A luz no fim do túnel é, na verdade, um trem que vem para atropelar os jovens. Na constatação de Antunes (1995), a partir de seus estudos sobre a diminuição dos postos de trabalho e aumento do trabalho precário, qualificação e competência não são garantia de emprego.

O discurso da competência permeia as questões ligadas ao trabalho jovem, pois a tendência é focalizar a esfera da Educação Profissional, que cada vez mais é influenciada por essas noções. Para Sarriera, Berlim, Verdim e Câmara (2000), não existem instrumentos institucionais que facilitem a transição escola - trabalho e a primeira inserção. O ingresso do indivíduo nesse mundo, que para o jovem é novo, fica por sua conta e passa a ser tratado ideologicamente no âmbito da competência. O jovem assume esse discurso, da ideologia neoliberal da meritocracia e do individualismo, reforçando a ideia de que existem indivíduos mais capazes que os demais e que, em função disso, conseguiriam se colocar no mercado, denunciando a incompetência de todos os outros que, supostamente, não desenvol- veram competências necessárias. Como consequência, verifica-se uma identidade fragilizada através da baixa autoestima e descrença em si mesmo. É necessário dialogar sobre essa realidade com os jovens de modo a criar estratégias para lidar com ela no âmbito pessoal e, coletivamente, participar do fomento para a criação de políticas públicas inclusivas.

\subsection{Identidade pessoal como noção de si e sentimento de si no mundo: categoria de análise e categoria sintese}

A Identidade é uma categoria de análise, ou seja, é um referencial. A partir da construção teórica "Identidade" (Ciampa, 2001), é possível enxergar e delinear um movimento da subjetividade humana, que é o do processo de produção de si mesmo, da singularidade a partir da diversidade. Essa produção vai ganhar corpo a partir da Atividade e da Consciência Pessoal (Góis, 1999; Leontiev, 1978), evidenciando a formação dinâmica da construção da humanidade em seus processos objetivos/subjetivos.

Essa é uma perspectiva da identidade em desenvolvimento, e não da identidade estática. O desenvolvimento da Identidade não acontece dentro de etapas pré-estabelecidas nem visa a atingir um estágio final. Também não acontece fora das possibilidades sociais concretas.

Identidade é representação de si. La Taille (2002) equivale a identidade ao conjunto de representações, de imagens de si, que estão carregadas de valores, localizados como centrais ou periféricos de acordo com sua importância.

Papéis são ações tipificadas dentro de um contexto, "de um acervo objetivado de conhecimentos comum a uma coletividade de atores. Os papéis são tipos de atores neste contexto" (Berger \& Luckmann, 1985 , p. 103). Para que os papéis possam ser construídos, é necessária a institucionalização da conduta. $\mathrm{O}$ ator passa a compreender a si mesmo a partir da ação que executa, realizando movimentos de identificação e reflexão sobre essa ação e organizando sua autoconsciência a partir das objetivações de si que acumula ao longo do tempo, daí a relação possível entre papéis e Identidade Pessoal. As personagens dizem respeito ao modo como os papéis são vivenciados. "Um papel, de fato, pelo menos em termos de Identidade, designa uma personagem" como ensina Ciampa (2001, p. 134). Pode-se compreender então que a personagem é o aspecto qualitativo do papel, aquilo que demarca sua singularidade, que torna possível a distinção entre aqueles que desempenham o mesmo papel.

Ciampa (2001) vai além das representações e considera que a Identidade aparece como a história de uma personagem, que é narrada pelo contador da história, pelo narrador/autor, que é, ao mesmo tempo, personagem. A história de uma personagem é vinculada a várias 
outras histórias. A partir da representação de si é possível chegar à análise da produção de si. Representação de si não é a representação de um papel, nem o somatório dos papéis assumidos. É a objetivação da subjetividade. Em cada momento da existência, há um aspecto da totalidade manifestando-se, um desdobramento das múltiplas possibilidades de ser. Essas possibilidades são determinadas nas relações sociais, que acontecem na atividade. Ser plenamente implica deixar de ser o que sempre foi para conseguir ser diferente e, ainda assim, o mesmo. É deixar de repor a identidade pressuposta.

Ciampa (2001) aborda a Identidade Pessoal a partir da noção de si. Góis (1995) aborda a mesma questão a partir do sentimento de si, fundamentando-se em Toro, Merleau-Ponty e Dilthey. A percepção de si brota do sentimento de estar vivo, que tem sua fonte na instância biológica, na corporeidade, expressão de uma totalidade possível apenas no imediatismo do momento presente. Em seus aspectos parciais, aparece como noção de si. Em seu aspecto de totalidade, aparece como sentimento de si.

Quando afirma que "diante do desconhecido, do indescritível, da não-estrutura, a identidade aflora com mais intensidade e cria um campo de presença onde o ser presentifica-se" (Góis, 1995, p. 56), o autor está de acordo com Heller (1985), quando esta diz que, diante de uma situação inesperada, para a qual o papel social do sujeito não serve de resposta, as características singulares aparecem.

Atividade e Consciência vão compor a Identidade, categoria síntese da compreensão da subjetividade pessoal, que não se encerra no indivíduo, mas efetua um desdobramento do singular e do social, compondo o modo como o ser humano constrói a realidade.

As concepções clássicas a respeito da Juventude focalizam bastante a questão da Identidade como momento de definição ou de crise. Tais perspectivas são incongruentes com esse referencial, que não compreende um momento específico da vida para tais eventos. A definição da Identidade, compreendida como manutenção e crise, ocorre a todo instante, nos momentos em que o sujeito (re)apresenta-se à sociedade e nos momentos em que se sente vivo em relação a tudo que vivencia. A condição do jovem na sociedade atual apresenta especificidades que esta investigação pretende abordar a partir da Psicologia Histórico-Cultural da Mente.

\subsection{Concepções de juventude desde a Psicologia Histórico-Cultural da Mente}

En la estructura de la personalidad del adolescente no hay nada que sea estable, definitivo e inmóvil. Todo en ella fluye y transmuta. (Vigotski, 1984)

$\mathrm{O}$ aspecto da transformação, do movimento, é uma marca constante no presente estudo, seja no modo como se compreende a Identidade, seja no reconhecimento das mudanças pelas quais passa o mundo do trabalho. A concepção de juventude da Psicologia Histórico-Cultural da Mente também ressalta esse fator, como demonstra Vigotski (1984), na epígrafe.

Vigotski (1984) alerta ainda para o excesso de estudos descritivos a respeito da juventude - idade de transição, como denomina esse momento da vida -, pois não são suficientes para compreender como se produzem as transformações e como se dão as importantes aquisições em termos das funções psicológicas superiores nessa idade.

Numa concepção histórico-cultural, é a partir do movimento dialético entre as relações sociais, cultura e singularidade, que a subjetividade humana vai se produzindo. Logo, as características da adolescência não seriam decorrentes do desenvolvimento natural do organismo ao longo do tempo. As mudanças do corpo são associadas a um momento significado, interpretado e construído socialmente. A partir daí, o jovem tem referência para construir sua identidade, convertendo o social em individual. $\mathrm{O}$ que acontece com o jovem na sociedade contemporânea, segundo Bock, Gonçalves e Furtado (2001), é o fato de que, mesmo já possuindo força e capacidade para ingressar no mundo adulto, não pode fazê-lo devido a uma necessidade de maior preparação para o trabalho. Essa necessidade de preparação é fruto do modo de produção capitalista. Está criado o cenário para a construção de uma "cultura jovem" que tem como elementos a busca da identidade, o conflito com as autoridades e a instabilidade entendidas como "naturais da idade".

Para Vigotski (1984), a idade de transição é o momento de formação das relações que possibilitam o surgimento da reflexão, pela passagem dos processos externos para os internos. Dessa forma, é possível surgir um movimento acabado e racional a partir de uma sucessão de estados psíquicos invisíveis. A consciência de si não é, portanto, resultante de um processo de autodescoberta, derivando do desenvolvimento cultural como uma das importantes aquisições da idade de transição. Durante a formação da autoconsciência, o jovem pode compreender as demais pessoas, o que apoia seu desenvolvimento social subsequente. A autoconsciência também regula os demais processos psicológicos superiores, como a atenção, a memória, o pensamento, a percepção e a ação, pelo estabelecimento de novas e complexas inter-relações entre eles. Estas novas conexões vão dar consistência à personalidade, transformando-a numa unidade presente em todas as ações realizadas pelo sujeito. O desenvolvimento da autoconsciência, da reflexão, subsidia, mesmo que em alguns momentos indiretamente, o modo pelo qual se dá o processo de produção dialético entre Identidade, 
Atividade e Consciência, forjando o Sujeito da Realidade e caracterizando o Trabalho como Atividade social significativa realizada por esse Sujeito.

A condição social afeta a construção do sujeito e, assim, Luria (1990) estudou a formação da capacidade de lidar com o próprio mundo interior, destacar e avaliar qualidades intrínsecas, ou seja, a autoanálise e a autoconsciência. Essas capacidades possibilitam a elaboração do autoconceito e são atividades mentais superiores e mais complexas, nas quais é possível assinalar a influência do meio social. O desenvolvimento humano se dá a partir de um substrato biológico e do acesso à cultura, de acordo com o que já foi explicitado no presente texto, a partir das considerações de Leontiev (1978).

\subsection{A dialética da exclusão/inclusão social: (re) produção de identidades}

Os mecanismos da cultura da pobreza (MartínBaró, 1998) e da ideologia de submissão e resignação (Góis, 1993) possibilitam a compreensão do modo pelo qual o movimento da Identidade é reposto, através do Caráter Oprimido e do Fatalismo.

"A cultura da pobreza é algo mais que a pobreza, é um estilo de vida que floresce em um determinado contexto social.” (Lewis, citado por Martín-Baró, 1998, p. 88). Essa cultura mantém-se através da "desesperança aprendida", ou do sentimento de impotência. Bosi (1992) faz alusão ao significado de cultura também como cultivo. Pode-se pensar, então, na cultura da pobreza como uma espécie de "fungo fatalista" que, uma vez arraigado ao indivíduo, não o abandona mais. Martín-Baró (1998) vai desvelar essa face do conceito, quando diz que a "transmissão" dessa cultura se dá muito mais no enfrentamento da realidade no cotidiano, irredutível a qualquer esforço de mudança, que por uma herança de valores familiares. Vale citar a passagem em que Martín-Baró rebate Lewis, quando este diz que "é muito mais difícil eliminar a cultura da pobreza que a pobreza em si" (Lewis, citado por Martín-Baró, 1998, p. 90). Parece mais difícil ainda, para Martín-Baró (1998), eliminar a cultura da pobreza sem eliminar o "cultivo" da pobreza.

O traço marcante do "estilo de vida" do pobre é, segundo Martín-Baró (1998), o fatalismo, que consiste em atribuir a falta de mudança nas condições em que vive a uma força superior, Deus, o Destino, ou qualquer outra entidade supranatural. Mesmo enganado a respeito da causa, o fatalismo traduz a verdade da falta de mudança nas sociedades latino-americanas, de acordo com o autor. A própria estrutura social desses países determina o fatalismo em última instância, "quando condena ao fracasso, de antemão, os esforços de superação que as pessoas possam realizar" (Martín-Baró, 1998, p. 95).
Portanto, o fatalismo é a interiorização da dominação, é uma das expressões da dominação no sujeito, que será analisada mais adiante. Por enquanto, explicita-se como essa interiorização se torna possível.

Entende-se, de acordo com Góis (1993), que o sistema capitalista sustenta-se mediante as desigualdades sociais que produz, gerando uma tensão social entre aqueles que estão se beneficiando do sistema e aqueles que se encontram excluídos desses benefícios. Para que essa tensão não alcance níveis capazes de destruir o sistema, foram criados mecanismos de manutenção que precisam funcionar na sociedade.

A Ideologia de Submissão e Resignação (Góis, 1993) é um desses mecanismos e está presente em todos os segmentos da sociedade, não apenas nos excluídos, reforçando o Caráter Oprimido (Góis, 1993). Todos os modos de produção cultural acima descritos estão mergulhados nessa ideologia, reproduzindo-a. É possível, segundo Góis (1993), observar a ação dessa ideologia desde o início da vida, durante a gestação, quando as privações que a mãe sofre deixam marcas profundas no desenvolvimento do indivíduo, ou seja, nada nesse sujeito vai estar preservado da marca da injustiça. A impotência está enraizada no fato de não ter nunca conhecido a sensação de ter as necessidades atendidas. As características da consciência semi-intransitiva, ou mágica, e da consciência transitiva-ingênua de Freire (1980), que marcam o estar no mundo do oprimido, são também engendradas na Ideologia de Submissão e Resignação. Martín-Baró (1998) faz inclusive referência a Freire (1980), quando discorre acerca da consciência mágica como sendo parte do caráter ideológico do fatalismo (Martín-Baró, 1998, p. 96). Com relação ao trabalho, é oportuna a análise de Guareschi (2001) a respeito do deslocamento das discussões a respeito da exploração do trabalhador para a exclusão do mundo do trabalho. A pressão pelo ingresso e manutenção do emprego - visto como acesso à cidadania - impede o questionamento das condições nas quais o trabalho é exercido, o que, somado ao individualismo, resulta no reforço da submissão.

A Ideologia de Submissão e Resignação é a rede tecida para manter o oprimido afastado da vida (Góis, 1993, p. 95), e o Fatalismo, bem como o Caráter Oprimido, são as marcas dessa teia no sujeito. Essa ideologia produz a cultura da pobreza e se expressa no excluído como Caráter Oprimido e Fatalismo.

\subsection{Fatalismo e caráter oprimido: expressão da exclusão no sujeito}

Para Martín-Baró (1998), o fatalismo é aquele modo de vida ou comportamento descrente na mudança e, por isso, acomodado, frequentemente encontrado nos 
povos latino-americanos. Segundo Góis (1993), o fato de a classe oprimida estar mergulhada na questão da sobrevivência vai produzir um estar no mundo diferente da classe mais favorecida, chamado de Caráter Oprimido, caracterizado por uma couraça psíquica, expressa inclusive a nível muscular, produzida inconscientemente pelo oprimido como reflexo primário de defesa ante a possibilidade de aniquilamento. Essa couraça deriva da necessidade de garantir a sobrevivência, que não está assegurada, não tendo a ver com uma psicopatologia.

A diferença entre os dois conceitos é que, na análise de Martín-Baró (1998), o Fatalismo exprime-se em termos de ideias, sentimentos e comportamentos. As ideias fatalistas dizem da predefinição da vida, impossível de ser transformada por qualquer ação. O papel da religião é ressaltado, e Deus é o responsável pela condição de vida das pessoas. Os comportamentos fatalistas são a submissão e o conformismo, além da tendência à passividade e da falta de memória e perspectivas, atendo-se ao presente. Os sentimentos fatalistas são a resignação, o distanciamento emocional e a aceitação.

Desse modo, apesar de reproduzirem a Ideologia de Submissão e Resignação, ou mesmo apresentarem ideias, sentimentos e alguns comportamentos fatalistas, a classe favorecida tem possibilidade de satisfazer suas necessidades de desenvolvimento pessoal, não se orientando somente para a sobrevivência e possivelmente não expressando as marcas da opressão no corpo em termos de Caráter Oprimido.

Como é possível pensar na possibilidade do desenvolvimento a partir de tal situação, quando todas as forças, da consciência, dos afetos e do corpo do sujeito, estão mobilizadas para a manutenção da exploração e da opressão dele mesmo? O Valor Pessoal e o Poder Pessoal são categorias sistematizadas por Góis (1993), que permitem uma análise das possibilidades de superação da situação de opressão.

\subsection{Valor pessoal e poder pessoal: o que move a metamorfose da identidade}

O Valor Pessoal, segundo o autor, é um sentimento que surge quando se está em contato com o núcleo de vida, que é a fonte da tendência atualizante, conceito de Rogers (1989) para definir a tendência humana para o desenvolvimento. Não se trata da construção de um modelo ideal de ser humano, mas da caracterização de um impulso para o desenvolvimento.

O contato com o núcleo de vida possibilita a capacidade de reconhecer em si e, consequentemente, no outro, essa humanidade, como possibilidade de transformação criativa do mundo, ou seja, como capaz de realizar trabalho e de se realizar no trabalho. Essa capacidade é expressão do Valor Pessoal: "Sentir-se capaz de viver, de gostar de si mesmo, acreditar na sua capacidade de conviver e realizar trabalho" (Góis, 1993, p. 73). Outra característica importante do Valor Pessoal é a capacidade de conviver, o que ressalta o caráter dialógico do ser humano.

O Poder Pessoal é o efeito do Valor Pessoal concretizando-se através da atuação da pessoa no mundo. Seria a capacidade de objetivar o potencial sentido no contato com o Núcleo de Vida, "a capacidade de influir na construção de relações saudáveis com os outros e com a realidade" (Góis, 1993, pp. 73-74). Rogers (1989, p. 10) diz ainda da possibilidade de transformação das relações de opressão pelo Poder Pessoal: "pessoas que confiam em seu próprio poder, não sentem necessidade de ter "poder sobre" e "estão dispostas a estimular e facilitar a força latente na outra pessoa".

O Valor Pessoal e o Poder Pessoal, como expressões que são da Identidade, forjam-se nas relações sociais. Na história da Severina, contada por Ciampa (2001), a metamorfose da identidade de Severina, de "doente mental" para "moleque aprontador e por isso deixando de ser moleque" (Ciampa, 2001, p. 86), somente acontece quando é possível a ela experimentar relações diferentes das costumeiras, interagindo com novas pessoas, com outros valores.

As limitações da perspectiva rogeriana ficam evidentes em relação a teorias mais críticas, uma vez que fica claro que a mudança pessoal não é suficiente para a alteração da estrutura social. O referencial, contudo, permite enfatizar a potência do sujeito diante de condições de desumanização.

Valor Pessoal e Poder Pessoal são os motores da metamorfose da identidade, ao mesmo tempo em que são expressões dessa metamorfose. A Ideologia de Submissão e Resignação, a Cultura da Pobreza e o Caráter Oprimido impedem o contato do indivíduo com o núcleo de vida e colaboram para a manutenção da Identidade.

\section{Aspectos metodológicos}

O enfoque qualitativo considera que conhecimento é o produto inacabado de um processo de construção da informação dentro de uma realidade que não está dada, mas que acontece na relação entre pesquisador e pesquisado. Sua legitimidade está amparada na qualidade, coerência e clareza da expressão dos sujeitos envolvidos no processo. Esta pesquisa inscreve-se nesse referencial, reconhecendo, contudo, que os critérios quantitativos também são importantes no relacionamento com a realidade.

Utilizou-se, para a coleta de dados, a técnica de Entrevista Orientada (Richardson, 1985). Foram realizadas três entrevistas com o participante ao longo de cinco meses, ou seja, o intervalo entre as entrevistas foi de no 
mínimo 60 dias. As primeiras entrevistas aconteceram ao longo do mês de julho, sendo as próximas realizadas em setembro e as últimas realizadas durante o mês de novembro do ano de 2004. O tempo de intervalo entre as entrevistas, bem como o período (a partir de três meses) de trabalho, considerado como critério de participação, são compreendidos como suficientes. No trabalho realizado na Prefeitura Municipal de Maracanaú, foi possível perceber mudanças, em questão de semanas, nos jovens que conseguem o primeiro emprego. De acordo com o referencial teórico deste estudo, considera-se que a identidade humana é plástica e também relacional. Ao se alterarem as relações que o indivíduo estabelece, sua identidade também se modifica. Considerar a necessidade de longos períodos de tempo para que se verifique algum movimento na Identidade Humana revela uma concepção estática do fenômeno.

Observa-se que a referência temporal das entrevistas foi o momento presente. Alusões ao passado e ao futuro foram feitas pelos participantes ou pela pesquisadora, à medida que facilitassem o aprofundamento sobre o tópico abordado. Cada entrevista foi realizada de modo a propiciar o aprofundamento da próxima, sendo incorporadas novas e diferentes perguntas para cada participante, a cada nova entrevista. As entrevistas foram transcritas seguindo o indicado por Koch (2000).

Depois de transcritas as entrevistas, o material foi organizado de acordo com a técnica da Análise Temática, que é, de acordo com Bardin (1977), uma das técnicas mais antigas e mais utilizadas em Análise de Conteúdo. Segundo López-Aranguren (1996), o objetivo das técnicas que compõem a Análise de Conteúdo é realizar inferências acerca de mensagens e comunicações, abarcando o conteúdo manifesto e podendo estender-se ao conteúdo latente.

Algumas das dimensões consideradas para a organização do material das entrevistas foram construídas anteriormente, para orientar a exploração da problemática de pesquisa, e outras derivaram do material produzido, obedecendo aos procedimentos de pré-análise, análise, tratamento e interpretação do material. O texto da entrevista transcrita foi recortado em unidades de análise (pontos significativos da fala), compondo os quadros temáticos a partir das dimensões: Momento Presente, Relações Familiares, Relações Sociais, Formação Escolar /Profissional, Período de Transição, Relações Profissionais, Expectativas e Percepção de $\mathrm{Si}$. A riqueza do material analisado sugere uma miríade de pontos cuja discussão seria relevante para a questão da juventude e trabalho. Os resultados apresentados a seguir, obtidos a partir da análise temática, foram expostos no sentido de elucidar o movimento da Identidade no trânsito de papéis e personagens na inserção profissional, objetivo da presente discussão.

\section{Resultados e discussão}

Sísifo, ao iniciar o processo da pesquisa, tinha 19 anos de idade. Morava com o pai e a mãe, aos quais sustentava a partir do trabalho como auxiliar de produção numa grande empresa de eletrodomésticos. Começou a exercer essa função por intermédio do Projeto Emprego Jovem, da Prefeitura Municipal de Maracanaú, em julho de 2003.

Para o jovem, que está construindo a autoconsciência (Vigotski, 1984), o momento de iniciação no mundo do trabalho pode criar uma maior necessidade de reflexão sobre si mesmo e suas condições de vida, colaborando para que a organização do cotidiano saia da ordem dos sentimentos fatalistas (Martín-Baró, 1998), de pouco Valor Pessoal (Góis, 1993), e caminhe para o exercício do Poder Pessoal. A vida de Sísifo, observada nos três momentos desta pesquisa, mostra um pouco desse processo.

O participante da pesquisa referiu-se à condição de arrimo de família como sendo a pedra à qual sua vida está atada, o que lhe rendeu o codinome de Sísifo neste estudo. Esse papel, arrimo de família, e a personagem filho-consciente, permanecem nos três momentos de entrevista. Durante o tempo em que sua história foi acompanhada, ser arrimo de família era o impeditivo da realização de suas possibilidades. Embora pensasse que "rolar a pedra" é castigo/missão divina, sabia que precisava dar seus passos para alterar a situação. Nas palavras de Camus: "Se há um destino pessoal, não há um destino superior ou pelo menos só há um, que ele julga fatal e desprezível. De resto sabe que é dono de seus dias" (Camus, 2004, p. 141). O Sísifo-que-se-torna-homem começou a se forjar no período de transição, quando começava a procurar trabalho, revelando aspectos do impacto da inserção profissional em sua Identidade:

logo depois [da conclusão do ensino médio] veio o baque, do pai ficar desempregado e eu ter que me tornar o homem dentro de casa, pra falar a verdade, então, a situação mudou um pouco, eu tive que pensar mais pro futuro do que pro passado. [incompreensível]. Então, tive que procurar emprego e tudo, batalhar. (Sísifo, comunicação pessoal, 29 de junho de 2004).

Ele reconheceu em si e em muitos jovens o despreparo em lidar com a nova realidade. Sentiu-se desqualificado e sem referenciais para lidar com a situação de inserção profissional. A fala também revela a falência da ilusão da noção de competência abordada na introdução deste trabalho:

Mas no seu curriculum você não pode dizer: eu sou inteligente, eu me destaco no meio da multidão. Não vai ser assim. Eu era um que pensava que ter o ensino médio fosse alguma garantia. E como eu, muitos. Acho que muitos, muitos mesmo pensam assim. E essa não 
é a realidade. (Sísifo, comunicação Pessoal, 29 de junho de 2004).

A fala seguinte traduz o impacto da política pública de inserção profissional na vida de um jovem como ele, para o qual o emprego formal se tornou uma questão de vida ou morte, e apresenta também a ausência de compreensão do que significou essa iniciativa, pela qual Deus recebe os créditos:

Graças a Deus, eu costumava me assustar quando o pessoal dizia quanto tempo procurou: 6 meses, 1 ano... Eu dizia assim: rapaz, tá ficando doido, eu vou morrer de fome! Só que eu recebi, por causa daquela palestra, eu recebi uma carta para fazer seleção na empresa atual, coincidentemente no mesmo dia que eu tinha feito a inscrição. (Sísifo, comunicação Pessoal, 29 de junho de 2004)

No tipo de consciência mágica, o sujeito entrega seu futuro a entidades supranaturais: Deus, Sorte, Destino. Sísifo manifesta esse tipo de consciência ao atribuir as dificuldades da sua vida a Deus, e o fato de melhorar no futuro à Sorte. Esse tipo de relação com a religiosidade também é característica do Fatalismo (Baró, 1998), conforme já explicitado, e sugere um entendimento particular a respeito da transformação da realidade forjada na submissão.

Em sua caminhada, Sísifo passou de estudante iludido para desempregado desiludido e desempregado realista. A sequência de papéis e personagens denota o movimento da Identidade de Sísifo no sentido de um maior contato com a realidade, mediada pela busca da colocação formal. Nessa busca, seus sonhos e projetos alteram-se, e Sísifo reformula a vida:

São dois momentos distintos: eu sai do colégio, sai com uma ilusão, saí com a ilusão de que eu ia arranjar emprego a hora que eu quisesse. E quando eu caí no mundo real eu tive que retraçar metas, retraçar sonhos e coisa e tal. (Sísifo, comunicação pessoal, 15 de novembro de 2004)

O movimento da sua identidade acontece quando, além de pensar a curto prazo, como exige a condição de arrimo, mantendo o papel e a personagem, Sísifo começou a forjar no presente estratégias de construção do futuro desejado. Considerou, acertadamente, que um treinamento na empresa em que trabalha pode ser também um momento de avaliação, engajando-se no processo e conseguindo uma promoção. Abandonar o papel de auxiliar de produção, assumido pela necessidade de sobrevivência, significou deixar um papel que o caracterizava como desqualificado:

Na verdade é sair do cargo de auxiliar que é o primeiro degrau... que como ela [a psicóloga] falou é o único cargo que não exige qualificação nenhuma... (Sísifo, comunicação pessoal. 04 de setembro de 2004)
Você passar a ser operador é ter uma profissão definida. Não que você fique satisfeito com aquilo, mas o fato de, pelo menos pra mim, o fato de deixar de ser auxiliar de produção já tira, vamos dizer, um peso das minhas costas (Sísifo, comunicação pessoal. 04 de setembro de 2004)

Ser operador, sua nova função, significou para ele o reconhecimento profissional, além da possibilidade de maior autonomia no trabalho. Outra passagem que demonstra como acontece o movimento da Identidade Pessoal de Sísifo, dentro da experiência de primeira inserção, é o movimento entre as personagens profissional revolucionário a submisso, falso.

Então eu não sabia ficar sem questionar, eu tinha que questionar... então, eu tenho uma nova maneira de lidar com pessoas, nem sei se isso é bom, porque eu tive que adquirir uma certa falsidade. Eu não sou sincero lá [na empresa]. (Sísifo, comunicação pessoal, 15 de novembro de 2004).

A personagem revolucionária aparentemente submeteu-se, continuando, porém, a existir, pois a submissão é falsidade. Desse modo, personagens contraditórios - revolucionário e submisso - coexistiram através de uma complexa teia de sentidos e significados, de modo a possibilitar uma expressão cada vez maior do Poder Pessoal (Rogers, 1989). Sísifo já não repetia o discurso da autoculpabilização, que o impediria de ver as próprias qualidades. O Valor Pessoal (Góis, 1993), ou seja, a possibilidade de gostar de si e aceitar-se, é mantido pelo movimento da consciência na análise da realidade social que o fazia diferente dos profissionais de nível superior, porém, igualmente inteligente:

Uma coisa que eu achei interessante lá foi ver, que quem é engenheiro, quem é mecânico, quem é chefe disso, daquilo e daquilo outro não é mais inteligente do que eu, só teve mais chances na vida. (Sísifo, comunicação pessoal, 15 de novembro de 2004)

Sísifo apresentou o trabalho como agente promotor de uma valorização de si de um modo bastante contraditório. Ao mesmo tempo em que fortalece o ser, a dignidade, o trabalho, ancora o valor à questão do ter, sendo essa a via de inclusão numa sociedade de valores consumistas. Leite (2003) assinala que, assim como no imaginário de Sísifo, em diversas pesquisas, antigas e recentes, o trabalhador é uma condição distinta do marginal. Desse modo, Sísifo deixou de sentir-se nada, para sentir-se digno e com valor:

Desde que eu comecei a trabalhar... não foi grande coisa... mas quando você começa a trabalhar você se sente... com valor. Eu já vi dizerem muito: você vale o quanto, o que você tem na carteira, e num mundo capitalista como o que é hoje, isso é realmente verdade. Então você começa a ter um outro raciocínio ... teve 
uma época na minha vida que eu pensei que não valia a pena, que não valia nada, que eu não representava nada na sociedade. Ai é que você passa a saber seu tipo de valor. Passa a ter valor no meio da sociedade. (Sísifo, comunicação pessoal, 15 de novembro de 2004)

Para além dessa contradição está, ainda, a função humanizadora da atividade. O valor de construir, apontado por Sísifo como aquilo que o faz sentir-se gente, pode ser compreendido dentro da teoria da psicologia histórico-cultural da mente, para a qual a relação entre atividade, consciência e identidade possibilita a Sísifo reconhecer a dimensão humana de si mesmo no trecho que segue:

A dignidade. Não que você não possa ter seu pensamento cristão, mas você se considera mais importante para a sociedade do que um marginal, do que um traficante, do que um... o trabalho torna você mais digno. Você troca um tempo da sua vida que você passa sem fazer nada, pensando besteira, passar um tempo produzindo, fazendo alguma coisa de futuro. Passar a construir. Você sente que tem valor quando você tem dignidade, não só pelo dinheiro. Como eu falei, ocasiões era pelo dinheiro, mas o trabalho me trouxe muita dignidade. Por outro lado também me fez sentir gente. (Sísifo, comunicação pessoal, $15 \mathrm{de}$ novembro de 2004)

A atividade humana significada aparece como processo de humanização, de construção de si. Ao transformar a natureza, transforma a si mesmo.

\section{Conclusão}

As palavras de Camus aparecem como despedida e como tradução dos sentimentos pelo autor/personagem/participante envolvido no processo de pesquisa :

Deixo Sísifo na base da montanha! As pessoas sempre reencontram seu fardo. Mas Sísifo ensina a fidelidade superior que nega os deuses e ergue as rochas. Também ele acha que está tudo bem. Esse universo, doravante sem dono, não lhe parece estéril nem fútil. Cada grão dessa pedra, cada fragmento mineral dessa montanha cheia de noite forma por si só um mundo. A própria luta para chegar ao cume basta para encher o coração de um homem. (2004, p. 141)

Esta investigação demonstra que o trabalho influencia o movimento da Identidade Pessoal de Sísifo. A partir do exposto na introdução do presente artigo, conclui-se que, nesse caso, a experiência de primeira inserção possibilita uma ligação maior com o núcleo de vida, fortalecendo o Valor Pessoal (Góis, 1993; Rogers, 1989). A partir do trabalho, Sísifo reconheceu a si mesmo como capaz: ligação do trabalho com a expressão do Poder Pessoal (Góis, 1993; Rogers, 1989). O participante vivenciou essas relações enquanto processo de hu- manização, a ontogênese da qual fala Leontiev (1978). Mediante o trabalho, Sísifo reformulou suas relações de um novo lugar social, aprendeu, de modo organizado ou não, e reinventou a si mesmo, "vendo o mundo com outros olhos": Identidade como Noção de Si. Encontra ainda força para lidar com as dificuldades cotidianas e sonhar: Identidade como Sentimento de Si.

Começar a trabalhar pode significar para os jovens começar a ser adulto. Esse processo de transição não acontece instantaneamente. De acordo com Sísifo, sua vida comportava o fato de ser jovem, trabalhador, filho e arrimo de família. Essas representações acontecem em meio a conflitos e harmonia, alternando-se e articulando-se a partir do trabalho, permitindo ver o reflexo do processo de inserção profissional.

As palavras de Leontiev são oportunas:

À primeira vista, e superficialmente, pode parecer que não ocorre, no fim do período da infância e da adolescência e com a passagem à vida profissional, qualquer mudança no lugar que ocupa o estudante no sistema das relações humanas. Mas não passa de uma aparência. ... Tornando-se um trabalhador, ocupa agora um lugar novo, a sua vida adquire um conteúdo novo e isto significa que vê doravante o mundo sob uma nova luz. (1978, p. 291)

Esse novo modo de ver o mundo foi bastante caracterizado no decorrer deste estudo, através da análise da vida de Sísifo e da relação dele com outros jovens pesquisados em outras ocasiões, pelos diversos autores aqui apresentados. Acontece na vida dos jovens um momento de reorganização da hierarquia dos motivos. Para Leontiev (1978), é preciso que as demandas adultas façam sentido dentro de uma esfera mais ampla de motivação social, ou serão rechaçadas. A relação com uma esfera de comunicação maior possibilita ao jovem um amplo conhecimento de si, ou, a partir de Vigotksi (1984), é possível dizer que a atividade vai alimentar a consciência, mobilizando o processo de formação da autoconsciência que acontece nesse período da vida. Assim, o trabalho adquire para muitos jovens de classes populares, inclusive para Sísifo, o sentido de aprendizado, socialização e fortalecimento da Identidade, de acordo com o aqui demonstrado.

Há ainda uma série de contradições que Sísifo não consegue articular, paradoxos que foram apresentados a partir de Antunes (1995) e Leite (2003): ser revolucionário e submisso, sua valorização como ser humano e o consumo, a realização profissional e pessoal em oposição ao sustento da família. Essas contradições relacionam-se com a discussão sobre a precarização do trabalho e o lugar do jovem frente a essas questões, o que faz pensar a facilitação da entrada no mercado ser insuficiente como medida isolada, pois as questões contextuais a respeito da vivência do jovem no mundo 
do trabalho contemporâneo, como as expressas nas contradições vividas por Sísifo, permanecem inalteradas em sua profundidade.

É preciso criar maneiras de acompanhar o jovem no início de sua vida profissional, de modo a facilitar objetiva e subjetivamente sua inserção no mundo do trabalho, bem como viabilizar políticas mais amplas de melhoria das condições de vida e de promoção da justiça social.

\section{Referências}

Antunes, R. (1995). Adeus ao trabalho? Ensaio sobre as metamorfoses e a centralidade do mundo do trabalho. São Paulo: Cortez.

Bardin, L. (1977). Análise de conteúdo. Rio de Janeiro: Edições Brasil.

Berger, P. \& Luckamnn, T. (1985). A construção social da realidade. Petrópolis, $\mathrm{RJ}$ : Vozes.

Bock, A. M. B., Gonçalves, M., \& Furtado, O. (Orgs.). (2001). Psicologia sócio-histórica: uma perspectiva crítica da psicologia. São Paulo: Cortez.

Bosi, A. (1992). Dialética da colonização. São Paulo: Companhia das Letras.

Camus, A. (2004). O mito de Sísifo. Rio de Janeiro: Record.

Ciampa, A. C. (2001). A estória do Severino e a história da Severina. São Paulo: Brasiliense.

Freire, P. (1980). Conscientização: teoria e prática da libertação. Uma introdução ao pensamento de Paulo Freire. São Paulo: Moraes.

Góis, C. W. de L. (1993). Noções de psicologia comunitária. Fortaleza: EDUFC.

Góis, C. W. de L. (1995). Vivência: caminho à identidade. Fortaleza: Editora Viver.

Góis, C. W. de L. (1999). Estudio de la relación entre actividad comunitaria y conciencia personal. Tese de Doctorado, Curso de influencia social: relaciones, procesos y efectos, Universidad de Barcelona, Barcelona.

Guareschi, P. (2001). Pressupostos psicossociais da exclusão: competitividade e culpabilização. In B. Sawaia (Org.), As artimanhas da exclusão - análise psicossocial e ética da desigualdade social (pp. 141-156). Petrópolis, RJ: Vozes.

Heller, A. (1985). O cotidiano e a história. São Paulo: Editora Paz e Terra.

Hirata, H. (1994). Da polarização das qualificações ao modelo de competência. In J. C. Ferreti, D. M. L. Zibas, F. R. Madeira, \& M. L. P. B. Franco (Orgs.), Novas tecnologias de trabalho e educação: um debate multidisciplinar (pp.128-142). Petrópolis, RJ: Vozes.

Koch, I. V. (2000). A inter-ação pela linguagem. São Paulo: Ed. Contexto.

La Taille, Y. (2002). Violência: falta de limites ou valor? uma análise psicológica. In H. W. Abramo, M. V. de Freitas, \& M. P. Sposito (Orgs.), Juventude em debate (pp. 110-134). São Paulo: Cortez.

Leite, M. de P. (1994). Modernização tecnológica e relações de trabalho. In J. C. Ferreti, D. M. L. Zibas, F. R. Madeira, \& M. L.
P. B. Franco (Orgs.), Novas tecnologias de trabalho e educação: um debate multidisciplinar (pp. 36-56). Petrópolis, RJ: Vozes.

Leite, E. M. (2003). Juventude e trabalho: criando chances, construindo a cidadania. In M. V. Freitas \& F. de C. Papa (Orgs.), Políticas públicas: juventude em pauta (pp. 153-172). São Paulo: Cortez; Ação Educativa Assessoria, Pesquisa e Informação; Fundação Friedrich Ebert.

Leontiev, A. (1978). O desenvolvimento do psiquismo. Lisboa: Livros Horizonte.

Lòpez-Aranguren, E. (1996). El análises de contenido. In M. G. Ferrando, J. Ibáñez, \& F. Alvira (Comps.), El análisis de la realidad social: Métodos y técnicas de investigación (pp. 461-492). Madrid: Alianza Editorial.

Luria, A. R. (1990). Desenvolvimento cognitivo: seus fundamentos culturais e sociais. São Paulo: Ícone.

Martín-Baró, I. (1998). Psicología de la liberación. Madrid: Editorial Trotta S.A.

Pochmann, M. (2002). Desenvolvimento, trabalho e solidariedade: novos caminhos para a inclusão social. São Paulo: Cortez Editora; Editora Fundação Perseu Abramo.

Richardson, R. J. (1985). Pesquisa social: métodos e técnicas. São Paulo: Saraiva.

Rogers, C. R. (1989). Sobre o poder pessoal. São Paulo: Martins Fontes.

Sarriera, J. C., Berlim, C., Verdin, R., \& Câmara, S. G. (2000). Os (des)caminhos dos jovens na sua passagem da escola ao trabalho. In J. C. Sarriera (Coord.), Psicologia comunitária: estudos atuais (pp. 45-64). Porto Alegre: Sulina.

Vigotski, L. S. (1984). Cap. 16. In L. S. Vigotski, Obras Escogidas (Vol. 4, pp. 225-248). Moscú: Editorial Pedagógica.

Recebido em: 27/04/2009

Revisão em: 06/09/2009

Aceite final em: 28/09/2009

Nara Maria Forte Diogo Rocha é Professora da Universidade Federal do Ceará. Mestre em Psicologia pela UFC. Endereço: Curso de Psicologia. Av. Lúcia Sabóia, 215. Centro. Sobral/CE, Brasil. CEP 62010-830. Email: naradiogo@hotmail.com

Cezar Wagner de Lima Góis é Professor da Universidade Federal do Ceará. Doutor em Influência Social: Processos e Efeitos pela Universidade de Barcelona. Endereço: Av. da Universidade 2762. Benfica. Fortaleza/Ceará, Brasil. CEP 60020-181. Email: cw154@gmail.com

\section{Como citar:}

Rocha, N. M. F. D. \& Góis, C. W. L. (2010). Trajetórias de jovens no mundo do trabalho a partir da primeira inserção: o caso de Sísifo em Maracanaú - Ceará, Brasil. Psicologia e Sociedade, 22(3), 466-475. 